\title{
Occurrence of familial spastic paraplegia in only one of monozygous twins
}

\author{
I. BONE, ${ }^{1}$ R. H. JOHNSON, AND M. A. FERGUSON-SMITH \\ From the Departments of Neurology and Medical Genetics, University of Glasgow, Glasgow
}

SYNOPSIS Three patients who suffer from spastic paraplegia are described who belong to two generations in one family. One of the patients, who has had symptoms and signs for at least 10 years, has a monozygous twin who is unaffected. Using blood groups and chromosomal polymorphisms, the probability of monozygosity is estimated to be 0.99986 . The observation of nonpenetrance in familial spastic paraplegia suggests that environmental factors may be involved in provocation and emphasises the need for careful genetic counselling in this and related diseases.

Strümpell $(1880,1893)$ described in two families a rare hereditary disorder characterised by progressive weakness and spasticity predominantly affecting the lower limbs with no evidence of other neurological deficit. Familial spastic paraplegia alone occurs much less commonly than spastic paraplegia associated with other neurological deficits and, in a review of 78 pedigrees reported in the world literature, only 28 of these had hereditary spastic paraplegia in a pure form (Bell and Carmichael, 1939). Nevertheless, pathological studies have supported the view that hereditary spastic paraplegia as defined by von Strümpell is a definite clinical and pathological entity (Schwartz, 1952; Behan and Maia, 1974). In Bell and Carmichael's patients, over half the pedigrees showed autosomal dominant inheritance and the others had recessive inheritance. Two families have been described with sex-linked recessive inheritance (Johnston and McKusick, 1962), but these did not have the pure form of the disorder. We now describe a father and daughter with pure spastic paraplegia, the aunt in the family also having this disorder. The daughter is one of a pair of identical twins and has had neurological symptoms and signs for at least 10 years. The other has no symptoms or signs. Such a dissociation in presentation of an apparently congenital disorder is remarkable in monozygous twins.

\footnotetext{
${ }^{1}$ Address for correspondence: I. Bone, Department of Neurology, St. James's Hospital, Leeds.

(Accepted 7 July 1976.)
}

\section{FAMILY M (Figure)}

Three patients (1: father, 2: aunt, 3 : daughter) with familial spastic paraplegia are described. The twin of patient 3 (subject 4) was free from the disease. The grandfather of the family was examined just before his death aged 88 years and no evidence of spasticity could be detected. The grandmother died at the age of 33 years from carcinoma, site unspecified. There is, then, no evidence of the disorder occurring in the first generation.

\section{PATIENT 1}

A.M., a male aged 58 years (Killearn Hospital, Glasgow, 21075), is one of four siblings. He entered the army when aged 23 years and then noticed stiffness in his legs on exertion, which had curtailed route marching, cross-country running, and cycling. In 1964 he was admitted to the Department of Neurosurgery at Killearn Hospital, Glasgow, for investigation. He was dragging both legs and had spasticity in all four limbs with bilateral ankle clonus and bilateral extensor plantar responses. Hoffman's sign was positive in the fingers, but no localised weakness could be detected and no other neurological signs were elicited. Investigations, including full blood count, urinalysis, and blood electrolytes were normal. Radiology of the cervical and lumbar spine were normal, but there was moderate scoliosis of the thoracic spine. Myelography was performed and this was normal. The CSF protein was $0.54 \mathrm{~g} / \mathrm{l}$, and WR and VDRL were negative. Eleven years later he had become progressively more disabled and was walking with the aid of hand crutches. He was, however, still 


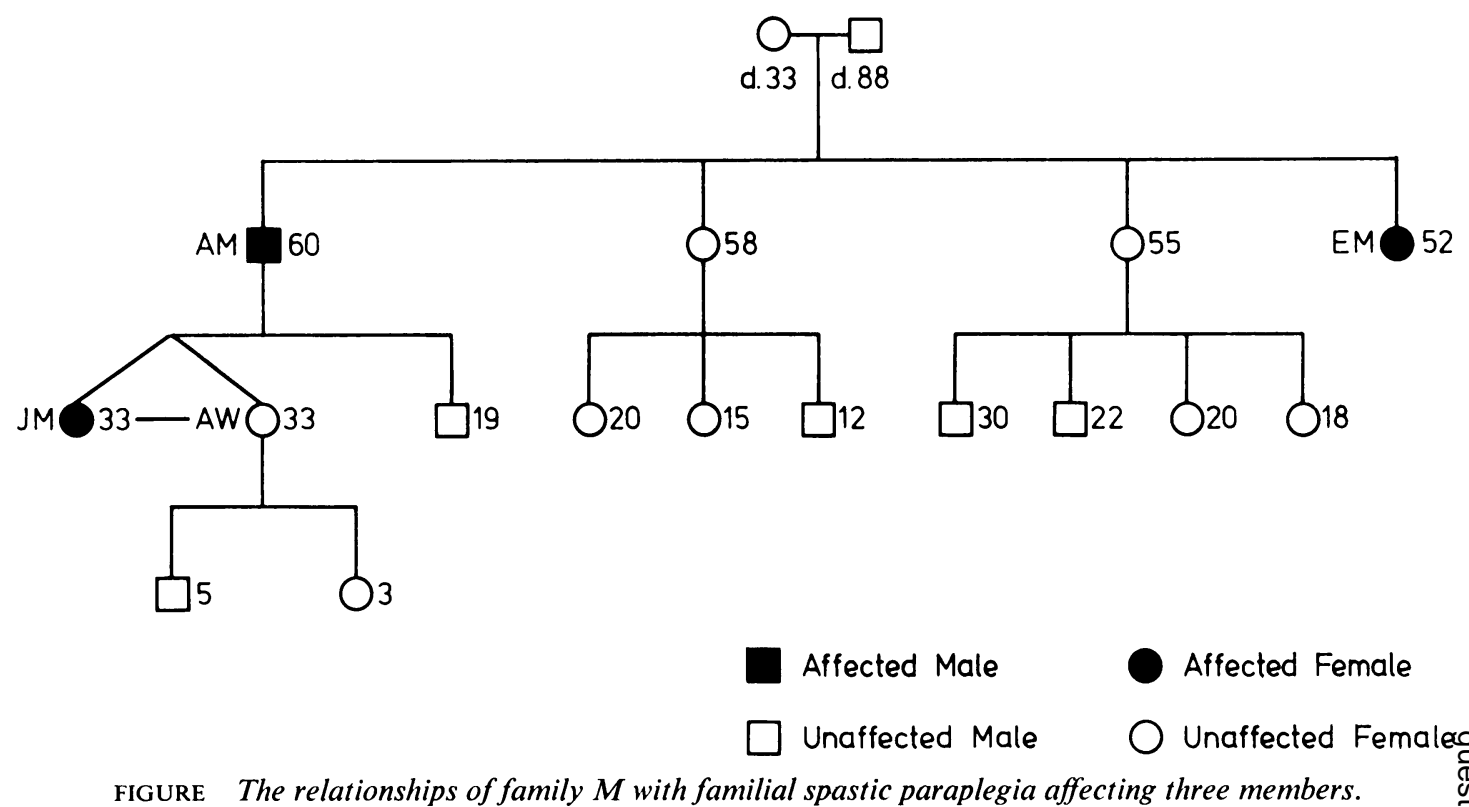

continuing to work as a telephone operator supervisor. He had a marked scissors gait with adductor spasm of both hips. He also had weakness of ankle dorsiflexion bilaterally, but his power was otherwise quite good. His reflexes remained as before and no other neurological signs were detected.

\section{PATIENT 2}

E.M., a female aged 52 years (Institute of Neurological Sciences, Southern General Hospital, Glasgow, 820873), is the youngest sibling of patient 1 . Since early adulthood she had been aware of stiffness in her legs, particularly after exercise. In the last seven years this had become more marked and she developed bilateral dropped foot. She had also noticed frequency of micturition. Examination in January 1975 showed a brisk jaw jerk and positive snout reflex, normal power and tone in the upper limbs with a positive Hoffman's reflex bilaterally. The lower abdominal reflexes were absent and there was generalised hyperflexia in the lower limbs with increase in tone, bilateral extensor plantar responses, and crossed adductor reflexes. Motor power was diminished in the lower limbs. Sensory testing was normal with the exception of loss of vibration sensation at the ankles. There were no abnormal cerebellar findings. Investigations including full blood count, ESR, urine analysis, blood urea and electrolytes, and $B_{12}$ and folate, were normal. WR and VDRL were negative. Myelography was performed and showed changes of mild cervical spondylosis with little evidence of ridging and no compression of the spinal cord. Cerebrospinal fluid contained a total protein of $0.23 \mathrm{~g} / 1$ with a gamma globulin of $0.01 \mathrm{~g} / 1(4 \%$ of total protein).

\section{PATIENT 3}

J.M., a female aged 33 years (Killearn Hospital, Glasgow, 198237), daughter of patient 1 and an identical twin of patient 4, presented in 1964 at the Centre for Rheumatic Diseases, Glasgow, with a twoyear history of painful stiff joints, particularly the knees and ankles. In 1965, general examination revealed nothing of note, her joints were not swollen and neurological examination was apparently normal. There was a slight flexion deformity of the right knee. ESR, full blood count, urinalysis, blood urea, and electrolytes were all normal and RA latex, LE cell, ANF, and thyroid antibody studies were negative. Liver function and protein electrophoresis of blood were normal. Viral studies were performed which showed no significant titre. Radiology of all joints failed to reveal any abnormality. The only untoward finding was an elevated ASO titre of 320 units $/ \mathrm{ml}$ compatible with a recent streptococcal infection, and it is uncertain whether her symptoms at this time were related to this or to the insidious development of her neurological disorder. Synovial membrane biopsy was performed from the knee joint and this was normal. Six months later it was noted that she had 
developed a right foot drop and in the next two years, during which her gait gradually deteriorated so that she required crutches for walking, she also developed adductor spasm of the right hip. The reflexes in her lower limbs were exaggerated, but her plantar responses were flexor. In 1967 she was referred to the Department of Neurology, Killearn Hospital, Glasgow, for further investigation. Examination essentially remained as before, but hyperreflexia in her lower limbs was demonstrated and both plantar reflexes were extensor. All investigations of blood were normal as before. Myelography was normal; CSF protein was $0.41 \mathrm{~g} / 1$. EMG studies were also normal. Since then there has been a progressive deterioration and mobility became more restricted. Orthopaedic procedures have been carried out in an attempt to correct contractures. In 1974 she developed occasional episodes of loss of consciousness for a few minutes. Three EEGs were normal, and it was felt that these events were probably functional. In 1974 she was admitted to the Institute of Neurological Sciences, Glasgow, for further assessment. She was alert and cooperative on examination and was wearing a spinal brace and a long-leg caliper on the right leg with a splint on the left leg. The right upper limb was held in a position of elbow and wrist flexion and was resistant to movement. There was a generalised increase of reflexes in the upper limbs. Abdominal reflexes were absent. Both lower limbs were held in a position of hip adduction and internal rotation, with flexion deformities of both knees and equinus deformities of both feet. The knee jerks were brisk and plantar responses were extensor, but ankle jerks were not elicited, perhaps as a result of bilateral surgical procedures in an attempt to elongate the tendo Achillis. There was marked wasting of the right peroneal muscles attributed to disuse. There was slight diminution of light touch sensibility in the lower extremities.

\section{PATIENT 4}

A.W., a female aged 33 years, was the daughter of patient 1 and the identical twin of patient 3. She had developed normally, had suffered from no serious illnesses and had had no operations. She was married with two children, enjoyed good health, and her gait was normal. Full neurological examination failed to reveal any abnormality: reflexes were all physiological, and there was no evidence of corticospinal dysfunction.

\section{GENETIC STUDIES}

Chromosome analyses and genetic marker studies were undertaken in the twins and their parents to provide confirmation that the twins were monozygous
(Table). The method used for calculating the probability of monozygosity is described by Race and Sanger (1975). Twenty-four polymorphic genetic loci including the loci for nine red cell antigens, the two main HLA histocompatibility loci, and the loci for six red cell enzymes and seven serum proteins were studied (Table), and of these the MNS, P, Kidd, haptoglobin, Gm, Gc, ACP-1, PGM-1, and HLA loci were informative.

Chromosome preparations from lymphocyte cultures were stained by Giemsa banding and quinacrine fluorescent techniques and examined for chromosomal polymorphisms. Two fluorescent polymorphisms were identified in both twins, a brightly fluorescent centric band of chromosome 3 of maternal origin and a brightly fluorescent centric band of chromosome 13 of paternal origin.

The twins proved to be concordant for all the markers tested. Combining the data from the chromosomal and other polymorphisms, the probability of

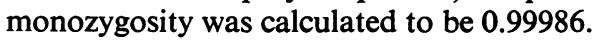

\section{DISCUSSION}

The clinical picture of familial spastic paraplegia is the development of progressive weakness and stiffness of the lower limbs and this may eventually spread to involve the upper limbs. Occasional disturbance of sphincteric function may occur in the later stages of the disorder. Cranial nerve involvement, however, would appear not to occur. In most families the ages of onset in affected siblings are close (Bell and Carmichael, 1939; Behan and Maia, 1974), but in a few families, particularly in different generations, the age of onset and rate of development are variable. A bimodal distribution of age of onset in the same family has been observed (Rhein, 1916). All affected patients described in this paper developed symptoms in the third decade of life but had a different clinical course. The condition of patients 1 (father) and 2 (aunt) has been slowly progressive and, while disabled, both have been able to lead a relatively normal life. Patient 3 (daughter) has had a rapid and disabling course because of contractures in the lower limbs, as reported in other patients by Bickerstaff (1950). Pathologically, lesions are confined entirely to the spinal cord with degeneration of lateral pyramidal tracts and also involvement of anterior corticospinal fibres. Slight degeneration in the lateral cerebellar pathways and degeneration in the tract of Goll have been noted (Schwartz, 1952; Behan and Maia, 1974).

The mode of inheritance of this disorder has been reviewed by Pratt (1967). Von Strümpell's (1880) original two families demonstrated autosomal dominant inheritance. The 27 members of a family described by Bickerstaff (1950) had members in three 


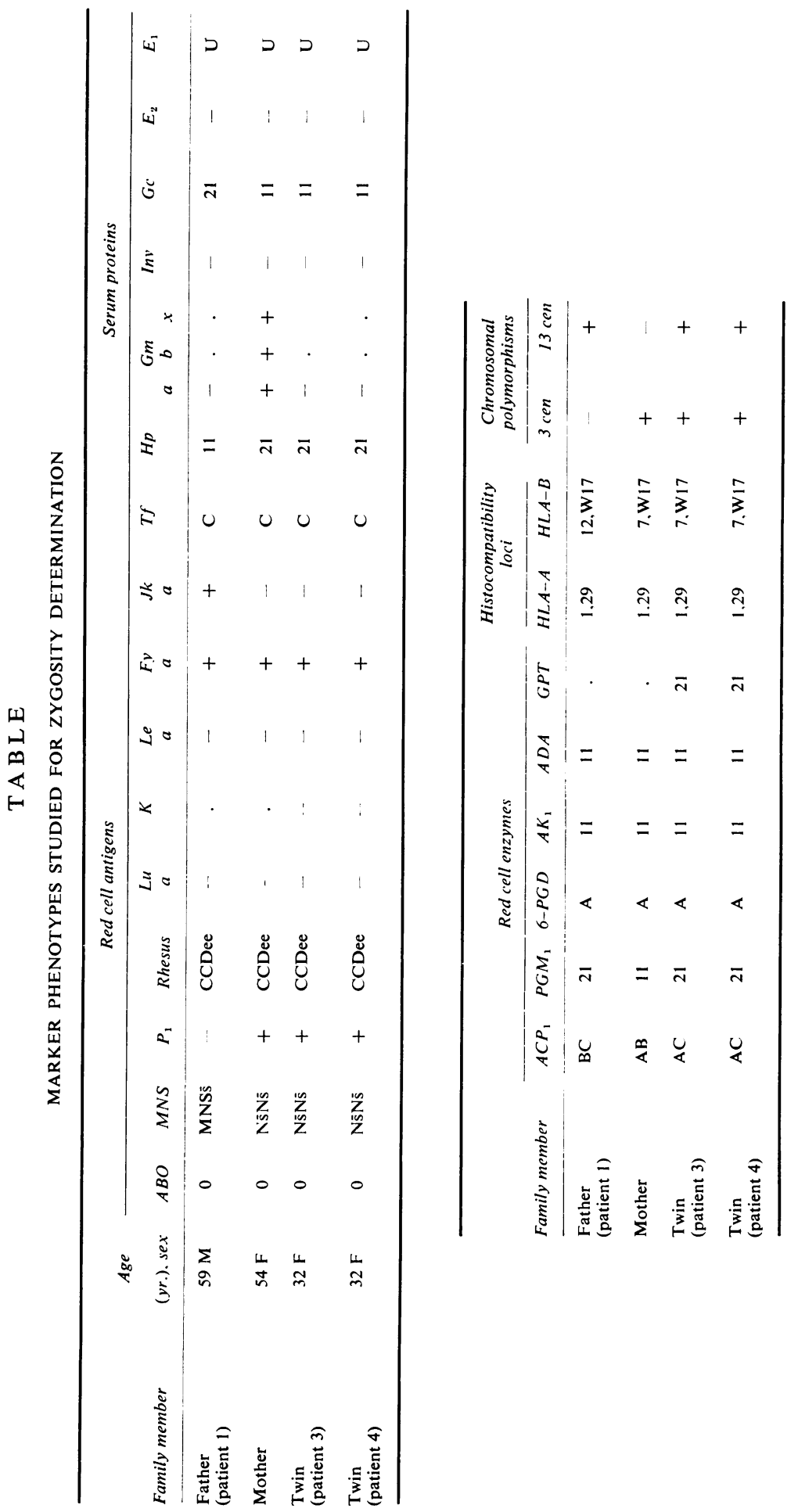


generations and also demonstrated autosomal dominant inheritance. Such patients usually develop their first symptoms around the age of 20 years but there may be delay. Bell and Carmichael (1939) also found evidence of recessive inheritance. The recessive forms tended to have an earlier onset (before the age of 10 years), and a more progressive clinical course. There is, however, considerable overlap, dominant forms sometimes presenting in childhood.

Chromosome analysis and genotyping confirm that patients 3 and 4 are almost certainly monozygous twins. Patients 1, 2, and 3 have a neurological disorder which clinically fits the description of von Strümpell and may be termed pure hereditary spastic paraplegia. Nevertheless, patient 4 is free of the disease even though her twin sister has been affected for at least 10 years, the most likely explanation being nonpenetrance of the gene. Analysis of affected families in the literature would indicate that patient 4 is unlikely to develop the disease herself, although there is a $50 \%$ chance of transmitting the gene to her children (Bell and Carmichael, 1939; Haldane, 1941a, b). The latter thus risk developing the disease themselves, unless the gene is again nonpenetrant. The family has been counselled on this basis and patient 4 has taken the decision to have no more children.

The term discordance is used when only one member of a pair of twins is affected by a disease process. In certain multifactorial disorders concordance is not the rule. In diabetes mellitus, concordance is found in $65 \%$ of monozygous twins and $20 \%$ of dizygous twins (see Parker, 1964). The genetic predisposition does not therefore always manifest itself unless triggered by environmental factors. In neurological disorders descriptions of discordance in monozygous twins have largely been confined to such heterogeneous and multifactorial deficits as epilepsy, cerebral palsy, arthrogryposis multiplex congenita (Hillman and Johnson, 1952), and micrencephaly, which can be explained perhaps as disorders of development (Parker, 1964). In hereditodegenerative disorders due to single gene defects discordance in monozygotic twins has been described in Huntington's chorea (Rosenthal, 1927), although monozygosity was not confirmed by genetic techniques. In these disorders, also, discordance may be related to environmental differences experienced by the twins.

The present cases therefore provide a further example of discordance in monozygous twins in a familial neurological disorder with an autosomal dominant mode of inheritance and variable expressivity. This demonstration of nonpenetrance of a serious genetic trait emphasises the need for careful genetic counselling in such families.
We wish to thank Professor W. B. Jennett for access to patient 1 , and Dr P. O. Behan for access to patient 2. R. H. Johnson wishes to thank Mr P. Freeman for referring patient 3 . We are most grateful to $\mathrm{Dr}$ Heather M. Dick for undertaking tissue typing in the family, and to Dr Elizabeth Winsor for assistance with the genetic studies.

\section{REFERENCES}

Behan, W. H. M., and Maia, M. (1974). Strümpell's familial spastic paraplegia: genetics and neuropathology. Journal of Neurology, Neurosurgery, and Psychiatry, 37, 8-20.

Bell, J., and Carmichael, E. A. (1939). On hereditary ataxia and spastic paraplegia. In Treasury of Human Inheritance, vol. 4, part 3, pp. 141-281. Cambridge University Press: London.

Bickerstaff, E. R. (1950). Hereditary spastic paraplegia. Journal of Neurology, Neurosurgery, and Psychiatry, 13, 134-145.

Haldane, J. B. S. (1941a). The partial sex-linkage of recessive spastic paraplegia. Journal of Genetics, 41, 141-147.

Haldane, J. B. S. (1941b). The relative importance of principal and modifying genes in determining some human diseases. Journal of Genetics, 41, 149-157.

Hillman, J. W., and Johnson, J. T. H. (1952). Arthrogryposis multiplex congenita in twins. Journal of Bone and Joint Surgery, 34A, 211-214.

Johnston, A. W., and McKusick, V. A. (1962). A sexlinked recessive form of spastic paraplegia. American Journal of Human Genetics, 14, 83-94.

Parker, N. (1964). Discordance in monozygote twins. Journal of Medical Genetics, 1, 88-94.

Pratt, R. T. C. (1967). Genetics of Neurological Disorders. Oxford Monographs on Medical Genetics. Oxford University Press: London.

Race R. R., and Sanger, R. (1975). Blood Groups in Man, 6th edn, p. 518. Blackwell: Oxford.

Rhein, J. H. W. (1916). Family spastic paralysis. Journal of Nervous and Mental Disease, 44, 115-144, 224-242.

Rosenthal, C. (1927). Zur Symptomatologie und Frühdiagnostik der Huntingtonschen Krankheit, zugleich ein Beitrag zur klinischen Erbforschung (Degenerationsersheinungen und Konstitutionsanomalian in einem Huntingtonstamm). Zeitschrift für die gesamte Neurologie und Psychiatrie, 111, 254-249.

Schwartz, G. A. (1952). Hereditary (familial) spastic paraplegia. Archives of Neurology and Psychiatry (Chic.), 68, 655-682.

Strümpell, A. (1880). Beiträge zur Pathologie des Rückenmarks. Archiv für Psychiatrie und Nervenkrankheiten, 10,676-717.

Strümpell, A. (1893). Über die hereditäre spastiche spinalparalyze. Deutsche Zeitschrift für Nervenheilkunde, 4, 173-183. 